\title{
Age differences in the effect of lateral displacing prisms (base left/20 diopter) on perception and walking
}

\author{
SHINJI ISHII \\ Hiroshima University, Hiroshima, Japan \\ and \\ SEYMOUR WAPNER \\ Clark University, Worcester, Massachusetts 01610
}

\begin{abstract}
Effects of short-term exposure to 11-deg lateral displacing prisms (base left/20 diopter) on perception and sensorimotor behavior (walking) was assessed in 24 5- to 7-year-old children and 24 adults. Walking tasks involved variation of feedback (walking along a straight line painted on the floor, walking toward a target) and carrying weight. Under prisms, it was found that: (1) three features of perception are affected significantly - physical horizontal appears rotated so that the left side is lower than the right, physical straight-ahead appears shifted to the right, and physical fronto-parallel plane appears rotated with right side closer to the subject than left; (2) relative to children, for adults the shifts are greater for both straight-ahead and fronto-parallel plane; (3) relative to children, adults walk rightward of the floor line to a differentially and progressively greater degree; (4) independent of age, walking rightward of the line is differentially greater when walking toward the target and walking without weight.
\end{abstract}

Relatively little work has been done on age differences in adaptation to vision rearranged by prisms. ${ }^{1}$ This is surprising since it is recognized that such studies may serve as valuable tools for studying sensorimotor and perceptual development; for example, Pick and Hay (1966) point to the value of assessing the flexibility of visual-motor functioning during development by this method. In the present study, it is generally assumed that rearrangement of vision by prisms involves changes on multiple levels of organismic behavior (on the sensorimotor, on the perceptual, and on the conceptual level); further, it is assumed that such changes vary depending on age of subject as well as on task and condition (Rierdan \& Wapner, 1966). As a first step in following up these assumptions which stress the relations among cognitive levels of organization, the present study has the following aim: To assess in 5- to 7-year-old children and adults the immediate effects (preexposure vs up to 10 min during exposure) of lateral displacing prisms

An abbreviated version of this paper was presented at the 21 st International Congress of Psychology, Paris, France, July 1976. This study was supported in part by Public Health Service Grant MH 00348 and in part by The Grant Foundation. We would like to thank the following people for their aid in completing this experiment: Dr. Richard Beschle, Daniel Funk, and Alec Pearsall for technical assistance. Patricia Dandonoli, Tamara Walker, and Liza Wofsey for their assistance in collecting the data; Karen Brown, Janet S. Cohen, and Stuart Selig for their assistance in analyzing the data; and Emelia Thamel for her help in preparing the manuscript. Requests for copies of this paper should be addressed to Seymour Wapner, Department of Psychology, Clark University, Worcester, Massachusetts 01610. (base left/20 diopter) on a number of features of space perception (apparent horizontal, straight-ahead, frontoparallel) and of sensorimotor action, as exemplified by walking.

A lateral displacing prism (base left/20 diopter) makes for lateral displacements of objects as well as for tilts; accordingly, while walking, the subject should exhibit correlative lateral displacements as well as arm, head, and trunk movements. Furthermore, assuming that tasks differing with respect to the availability of feedback (cf. Held, 1961; Held \& Freedman, 1963) also play a significant role in effect of visual rearrangement by prisms, differences are expected between walking toward a target (lesser feedback) as compared with walking along a line with feet visible (greater feedback), and while carrying as compared with not carrying a pack (6 lbs). Finally, since children and adults are presumed to differ in terms of perceptual and motor adaptability, and with respect to differentiation between action and perception, differences were expected between the 5- to 7-year-old child and the adult in the impact of prismatic rearrangement on perception, walking, and their relationship. ${ }^{2}$

\section{METHOD}

To assess the effect of these variables, 24 5- to 7-year-old children and 24 adults were compared with respect to the immediate impact of introducing "base-left 20-diopter" prisms (cf. Rock, 1966 for a qualitative description of perceptual effects of this prism) on (1) space perception and (2) walking under various conditions. 


\section{Perception}

In all three perceptual tasks, the subject's head was fixed in a headrest. There were two trials without prisms and two trials with prisms for each of the three perceptual tasks. ${ }^{3}$ Prism conditions utilized base-left 20-diopter lenses (approximately 11-deg displacement to the right) and plano lenses were used under control conditions. On apparent horizontal, the task for the subject was to tell the experimenter how to rotate a rod, initially placed at physically horizontal, so that it appeared horizontal, that is, appeared straight across, not slanted. On apparent straight-ahead, the subject was to tell the experimenter how to move the line (toward left or right), initially placed at physically straight-ahead, so that it appeared straight-ahead, that is, appeared directly in front of the subject's nose. On apparent fronto-parallel, the subject was to indicate to the experimenter how to rotate a board (right edge away and left edge toward subject or vice versa), initially placed at physical fronto-parallel, into a position so that it appeared fronto-parallel.

\section{Walking}

The procedures for the walking tasks were as follows: After practicing walking in time with a metronome beating at the rate of 1.2 beats/sec, the subject carried out the walking tasks, without prisms and with prisms. The subject walked for a distance of $35 \mathrm{ft}$ under each of two feedback conditions: (1) line (relatively greater feedback)-walking along a line painted on the floor, with tips of feet visible ("Look down at the line on the floor just in front of your toes and walk along it as if you were walking along a tight rope or a fence"); (2) target (lesser feedback)walking toward a clock located $51 / 2 \mathrm{ft}$ above the floor in a plane which was a direct extension of the line but $10 \mathrm{ft}$ beyond the stopping point at the end of the line ("Walk as straight as you can toward the center of the clock in front of you").

Walking behavior was recorded by means of a two-camera split-screen video system, with half of the screen showing the back of the subject walking away from the camera and the other half of the screen showing the front of the subject walking toward the camera. An event recorder was used to time the entire 35-ft distance traveled from the starting position, as well as the time at which the subject passed each of the markers located at 5-ft intervals.

The sequence of test conditions, both within perceptual and walking situations and among them, was controlled systematically, except that all trials without prisms preceded those with prisms. Within each test condition, there were two trials. Two 5- to 7-year-old children were tested in each sequence. For the walking conditions one of the children and one of the adults in each sequence were tested with back packs (mean of $6 \mathrm{lbs}$ ); the other two were tested without back packs.

\section{RESULTS}

\section{Perception}

Apparent horizontal. With prisms on, the physical objective horizontal appears rotated $\mathrm{CCW}$, that is, with left side of the physically horizontal rod appearing lower relative to right side. To adjust the rod so that it appears horizontal, it must be rotated CW (Mean $=2.0 \mathrm{deg} \mathrm{CW}$ ) to a greater degree under prisms compared with control conditions $($ Mean $=.3 \mathrm{deg} \mathrm{CW})(\mathrm{F}=25.04, \mathrm{df}=1 / 44$, $\mathrm{p}<.01)$.

Apparent straight-ahead. With prisms on, for both children and adults, the physical straight-ahead appears shifted to the right. To adjust the rod to a position that appears straight-ahead, the vertical line must be adjusted more to the left (Mean $=-0 \mathrm{deg} 47 \mathrm{~min})$ under prisms compared with control (no-prism) conditions (Mean = to deg $9 \mathrm{~min}$ ). The overall prism effect is significant $(\mathrm{F}=9.92, \mathrm{df}=1 / 44, \mathrm{p}<.01)$. The interaction of Age by Prism is also significant $(F=5.58, d f=1 / 44, p<.05)$. The mean scores for prism and no-prism conditions are, respectively, -0 deg $14 \mathrm{~min}$ and $-0 \mathrm{deg} 3 \mathrm{~min}$ for children; for adults they are $-1 \mathrm{deg} 19 \mathrm{~min}$ and $+0 \mathrm{deg} 19 \mathrm{~min}$, respectively. The difference between prism and control conditions $^{4}$ is not significant for children $(F=.38$, $\mathrm{df}=1 / 46, \mathrm{p}>.05)$ and is significant for adults $(\mathrm{F}=2.76$, $\mathrm{df}=1 / 46, \mathrm{p}<.01)$. Stated in terms of the location of the physical straight-ahead, prism has no effect for children, but for adults under prisms the shift of the physical straight-ahead to the right is statistically significant.

Apparent fronto-parallel. In terms of adjustment of the board, the overall effect of prisms is significant $(\mathrm{F}=63.45, \mathrm{df}=1 / 44, \mathrm{p}<.01)$, with prism yielding a mean score of $4.4 \mathrm{deg} \mathrm{CCW}$ (right edge rotated out of fronto-parallel plane away from subject) as compared with control (no prism) for which the mean score was $.5 \mathrm{deg}$ CCW. The Age by Prism interaction is significant $(F=4.31, \mathrm{df}=1 / 44, \mathrm{p}<.05)$. For both children and adults, in order to be seen as fronto-parallel, the board is adjusted with right edge further from the subject; however, the shift is significantly greater in adults (mean prism $=5.0 \mathrm{deg} \mathrm{CCW}$, mean control $=.3 \mathrm{deg} \mathrm{CCW}$ ) than in children (mean prism $=3.5 \mathrm{deg} \mathrm{CCW}$, mean control $=$ $.6 \mathrm{deg} \mathrm{CCW}$ ). (For children: $\mathrm{t}=2.94, \mathrm{df}=1 / 46, \mathrm{p}<.01$; for adults: $t=5.04, d f=1 / 44, p<.001$.) Thus, for both children and adults under prisms, the physically true fronto-parallel plane appears rotated so that the right edge looks closer to the subject than does the left side; this effect is significantly greater in adults than in children.

\section{Walking}

The main findings for the major variables, prism and age, and their interaction are as follows:

1. Under prisms, walking is progressively rightward of the floor line with greater distance from the starting point; moreover, these differences are greater in the adult than in 5- to 7-year-old children (see Table 1).

\section{Table 1}

Effect of Lateral Displacing Prisms (20 Diopter/Base Left) on Walking Behavior in 5- to 7-Year-Old Children and Adults* [Deviation (Centimeters) From Floor Line]

\begin{tabular}{llrrrrrrr}
\hline \multirow{2}{*}{$\begin{array}{c}\text { Age } \\
\text { Group }\end{array}$} & $\begin{array}{c}\text { Condi- } \\
\text { tion }\end{array}$ & \multicolumn{6}{c}{ Checkpoint (Feet From Starting Point) } \\
\cline { 2 - 9 } Child & \multicolumn{1}{c}{10} & 15 & 20 & 25 & 30 & 35 \\
\hline \multirow{4}{*}{ Adult } & Prism & 10.5 & 11.5 & 13.3 & 13.2 & 14.4 & 14.4 & 14.4 \\
& No Prism & .0 & .0 & .0 & .0 & .0 & .0 & .1 \\
& Prism & 17.0 & 20.0 & 22.7 & 23.9 & 27.5 & 30.7 & 31.5 \\
& No Prism & .0 & .4 & .1 & .1 & .1 & .6 & .2 \\
\hline
\end{tabular}

${ }^{*} F=6.60, d f=6 / 240, p<.05$ 
2. Under prisms, there is differentially greater left arm movement for the children relative to adults, when not carrying weight (no back pack). ( $\mathrm{F}_{\mathrm{A}}$ by $\mathrm{P}$ by $\mathrm{B}=$ 4.03, $\mathrm{df}=1 / 40, \mathrm{p}<.05$.)

3. Independent of other conditions, children show greater left and right arm movement than adults (Left arm: $F=7.77, \mathrm{df}=1 / 40, p<.01$. Right arm: $F=17.73$, $\mathrm{df}=1 / 40, \mathrm{p}<.01$.

There were a number of secondary findings:

1 . Walking rightward of the floor line shows significantly greater deviation: (a) without weight (no back pack) than with weight (back pack) $(\mathrm{F}=5.00, \mathrm{df}=1 / 40$, $\mathrm{p}<.05)$; (b) the further from the starting point $(\mathrm{F}=$ 19.92, df $=6 / 240, p<.01$ ); and (c) under target (lesser feedback) than under line (greater feedback) conditions $(\mathrm{F}=23.66, \mathrm{df}=1 / 40, \mathrm{p}<.01)$.

2 . Left and right arm movement are significantly greater: (a) when walking along the line (greater feedback) than when walking toward the target (lesser feedback) $(\mathrm{F}=25.10, \mathrm{df}=1 / 40, \mathrm{p}<.01)$, and (b) when walking without weight (no back pack) than when carrying weight (back pack) $(\mathrm{F}=4.87, \mathrm{df}=1 / 40, \mathrm{p}<.05)$.

3. Speed of walking is: (a) slower in children $(F=$ 11.41, df $=1 / 40, p<.01$ ); (b) slower when carrying weight (back pack) conditions $(\mathrm{F}=12.62, \mathrm{df}=1 / 40$, $\mathrm{p}<.01$ ); (c) slower when walking along the line (greater feedback) than toward target (lesser feedback) $(F=53.42$, $\mathrm{df}=1 / 40, \mathrm{p}<.01$ ); and (d) increased from start to $25 \mathrm{ft}$ and then decreased during the last $10 \mathrm{ft}$. $(F=16.72$, $\mathrm{df}=6 / 240, \mathrm{p}<.01)$.

\section{DISCUSSION}

The main contribution of the present study is that parallel changes in effect of lateral displacing prisms occur on the sensorimotor and perceptual levels and, most important, that these effects are largely of lesser magnitude in 5- to 7-year-old children compared with adults.

This finding of more rapid adaptation to visual rearrangement by prisms in 5- to 7-year-old children is consonant with the findings by Devoe (1969) and Giannitrapani (1958). These investigators also found greater adaptation to prism rearrangement in children. Such more rapid adaptation in children, however, is incongruous with the lack of significant age differences in studies by various other investigators, such as Pick and Hay (1966), Smothergill, Martin, and Pick (1971), and Wallace and Anstadt (1974). While there is perhaps too little work done in this area to make very general conclusions regarding age differences in adaptation, parallel findings for both perception and sensorimotor action (walking) have significance. The argument for differential age differences in adaptation is strengthened because both perception and sensorimotor action are affected analogously by lateral displacing prisms. These findings are in agreement with Rock's (1966) dictum that the effect of lateral displacing prisms on sensorimotor action should parallel the effects on perception. However, the relationship between perception and sensorimotor behavior is only correlative and thereby inconclusive with respect to the issue of whether the primary change in adaptation is perceptual, as proposed by Rock (1966) or is sensorimotor, as proposed by Held and his associates (e.g., Held \& Freedman, 1963; Held \& Hein, 1958). From the holistic viewpoint of organismic- developmental theory (Rierdan \& Wapner, 1966; Wapner, Cirillo, \& Baker, 1969), it is of significance that both levels of cognitive organization are involved in the adaptation process.

To advance our understanding of age differences in adaptation uncovered here and in the other isolated studies where they have been obtained, empirical studies and theoretical conceptualization are required. The empirical investigations might profitably involve parametric studies similar to the present study, but with a larger sampling of diverse age groups. Empirical study would also profit from introduction of the aftereffect paradigm on studies of age differences and from studying systematically the interrelations among the sensorimotor, perceptual, as well as the conceptual levels of organization in prism adaptation. To do so, theoretical constructs must be developed that are capable of handling the impact of and adaptation to prisms on the interrelations among levels of cognitive organization at different stages of development.

\section{REFERENCES}

Devoe, S. T. Age differences in adaptation to visual rearrangement by prisms (Doctoral dissertation, Clark University, 1969. University Microfilms No. 58-7084)

Epstein, W. Varieties of perceptual learning. New York: McGraw-Hill, 1967.

Giannitrapani, D. Changes in adaptation to prolonged perceptual distortion: A developmental study (Doctoral dissertation, Clark University, 1958. University Microfilms No. 58-7084)

HeLd, R. Exposure-history as a factor in maintaining stability of perception and coordination. Journal of Nervous and Mental Disease, 1961, 32, 26-32.

Held, R., \& Hein, A. Adaptation of disarranged hand-eye coordination contingent upon re-afferent stimulation. Perceptual and Motor Skills, 1958, 8, 87-90.

Held, R., \& Freedman, S., JR. Plasticity in human sensorimotor control. Science, 1963, 142, 455-462.

KIRK, R. E. Experimental design: Procedures for the behavioral sciences. (2nd ed.) Belmont, Calif: Brooks/ Cole, 1969.

Pick, H. L., JR., \& HAY, J. C. The distortion experiment as a tool for studying the development of perceptual-motor coordination. In N. Jenkin \& R. H. Pollack, Proceedings of a conference on perceptual development: Its theories of intelligence and cognition. Chicago: Institute for Juvenile Research and National Institutes of Health, 1966.

RIERdan, J. E., \& WAPNER, S. Experimental study of adaptation to visual arrangement deriving from an organismic-developmental approach to cognition. Perceptual and Motor Skills, 1966, 23, 903-916.

Rock, I. The nature of perceptual adaptation. New York: Basic Books, 1966.

Smith, K. U., \& Greene, P. A. Critical period in maturation of performance with space-displaced vision. Perceptual and Motor Skills, 1963, 17, 627-639.

Smothergill, D. Q., Martin, R., \& Pick, H. L., JR. Perceptual-motor performance under rotation of the central field. Journal of Experimental Psychology, 1971, 87, 64-70.

Wallace, B., \& Anstadt, S. P. Target location aftereffects for various age groups. Journal of Experimental Psychology, 1974, 103, 175-177.

Wapner, S., Cirillo, L., \& Baker, A. H. Sensory-tonic theory: Toward a reformulation. Archivio di Psicologia Neurologia e Psichiatria, 1969, 30, 493-512.

Warren, D., \& Platr, B. B. The subject: A neglected factor in recombination research. Perception, 1974, 3, 421-439. 


\section{NOTES}

1. Exceptions include such studies on age differences as those by Devoe (1969), Giannitrapani (1958), Pick and Hay (1966), Smith and Greene (1963), Smothergill, Martin, and Pick (1971), and Wallace and Anstadt (1974); yet the Kansas Conference of 1973, for instance, does not mention age difference even though one article (Warren \& Platt, 1974) points to the importance of individual differences in adaptation to visual rearrangement through prisms. Similarly, no mention is made of age differences in effect of visual rearrangement by prisms in Epstein's (1967) review.
2. Indeed, Devoe (1969) found preliminary evidence that with lateral displacing prisms children 6 years and younger walked with body tilted left and older children walked with body tilted right.

3. The prisms were worn in Universal trial frames manufactured by the Bernell Corporation, South Bend, Indiana, which were adjustable for use by both children and adults.

4. Assessed by a t test (see Kirk, 1969, p. 266f).

(Received for publication January 21, 1977.) 